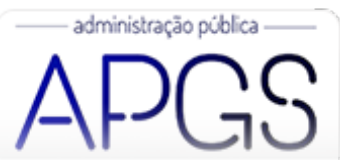

Administração Pública e Gestão Social ISSN: 2175-5787

apgs@ufv.br

Universidade Federal de Viçosa

Brasil

\title{
Engajamento no Trabalho: Conceitos, Teorias e Agenda de Pesquisa para o Setor Público
}

Reis de Souza Camões, Marizaura; Oliveira Gomes, Adalmir

Engajamento no Trabalho: Conceitos, Teorias e Agenda de Pesquisa para o Setor Público

Administração Pública e Gestão Social, vol. 13, núm. 3, 2021

Universidade Federal de Viçosa, Brasil

Disponible en: https://www.redalyc. org/articulo. $0 a ?$ id=351566982005 


\title{
Engajamento no Trabalho: Conceitos, Teorias e Agenda de Pesquisa para o Setor Público
}

\author{
Work Engagement: Concepts, Theories and Research Agenda for the Public Sector \\ Compromiso en el trabajo: conceptos, teorías y agenda de investigación para el sector público \\ Marizaura Reis de Souza Camões \\ Universidade de Brasilia, Brasil \\ Redalyc: https://www.redalyc.org/articulo.oa? \\ id $=351566982005$
}

marizaurareis@gmail.com

Adalmir Oliveira Gomes

Universidade de Brasilia, Brasil

adalmirdeoliveira@gmail.com

Recepción: 19 Junio 2020

Aprobación: 02 Enero 2021

Publicación: 01 Julio 2021

\section{Resumo:}

Objetivo da pesquisa: sistematizar o conhecimento produzido, propor um marco analítico conceitual e uma agenda de pesquisa para o estudo do engajamento no trabalho no setor público brasileiro.

Enquadramento teórico: o ensaio apresenta, além da evolução conceitual, as principais teorias que dão suporte para os estudos de engajamento no trabalho - job demands-resources theory (JD-R), social exchange theory (SET), teoria de conservação de recursos e broaden-and-build theory.

Metodologia: foram realizadas duas sistematizações na literatura: i) conceitos, teorias, modelos, resultados e moderadores de engajamento no trabalho e ii) análise de 27 estudos sobre engajamento no trabalho em organizações brasileiras.

Resultados: o estudo apresenta a sistematização do conhecimento produzido a respeito de engajamento no trabalho, com ênfase no setor público, identifica lacunas na literatura sobre o tema, em especial no contexto brasileiro, e propõe um marco analítico conceitual e uma agenda de pesquisa para estudos futuros sobre o tema em organizações no setor público nacional.

Originalidade: os resultados apresentados contribuem para suprir a ausência, na literatura nacional, de artigos que façam uma discussão teórica de forma integradora do conhecimento produzido sobre engajamento no trabalho. Além disso, propõe de forma inédita um marco analítico conceitual para o engajamento no trabalho no setor público.

Contribuições teóricas e práticas: Os resultados contribuem para acadêmicos e practitioners no entendimento das causas e consequências do engajamento no trabalho no âmbito da administração pública, ajudando nortear a proposição de intervenções em políticas públicas e práticas de gestão de pessoas em organizações públicas.

Palavras-CHAVE: engajamento no trabalho, antecedentes e resultados, setor público brasileiro, agenda de pesquisa.

\section{Abstract:}

Objective: The objective of this research is to systematize the produced knowledge, proposing a conceptual analytical framework and a research agenda for the study of work engagement in the Brazilian public sector.

Theoretical framework: the essay presents, in addition to the conceptual evolution, the main theories that support the studies of work engagement - job demands-resources theory (JD-R), social exchange theory (SET), resource conservation theory and broaden-and-build theory.

Methodology: two systematizations were produced from the academic production in the field: i) concepts, theories, models, results and moderators of work engagement, and ii) analysis of 27 studies on work engagement in Brazilian organizations.

Results: the study presents the systematization of the produced knowledge about work engagement, emphasizing on the public sector, identifies literature gaps, especially in the Brazilian context, and proposes a conceptual analytical framework and a research agenda for future studies in the national public sector organizations.

Originality: the results presented contribute to supply the absence, in the Brazilian literature, of articles that make a theoretical discussion in an integrative way of the produced knowledge about work engagement. In addition, it proposes in an unprecedented way a conceptual analytical framework for work engagement the public sector. 
Theoretical and practical contributions: The results contribute to academics and practitioners in understanding the causes and consequences of work engagement within the scope of public administration, helping to guide the proposition of interventions in public policies and human resources practices in public organizations.

KEYWORDS: work engagement, antecedents and results, Brazilian public sector, research agenda.

\section{Resumen:}

Objetivo de la investigación: sistematizar el conocimiento producido, proponer un marco conceptual analítico y una agenda de investigación para el estudio del compromiso en el trabajo en el sector público brasileño.

Marco teórico: el ensayo presenta, además de la evolución conceptual, las principales teorías que sustentan los estudios del compromiso en el trabajo - job demands-resources theory (JD-R), social exchange theory (SET), resource conservation theory and broaden-and-build theory.

Metodología: se realizaron dos sistematizaciones en la literatura: i) conceptos, teorías, modelos, resultados y moderadores del compromiso en el trabajo y ii) análisis de 27 estudios sobre compromiso en el trabajo en organizaciones brasileñas.

Resultados: el estudio presenta la sistematización del conocimiento producido sobre el compromiso en el trabajo, con énfasis en el sector público; identifica vacíos en la literatura sobre el tema, especialmente en el contexto brasileño; y propone un marco conceptual analítico y una agenda de investigación para futuros estudios sobre el tema en organizaciones del sector público nacional.

Originalidad: los resultados presentados contribuyen a suplir la ausencia, en la literatura nacional, de artículos que realicen una discusión teórica de manera integradora del conocimiento producido sobre el compromiso en el trabajo. Además, propone de manera inédita un marco conceptual analítico para la participación en el trabajo en el sector público.

Aportes teóricos y prácticos: Los resultados contribuyen a que académicos y profesionales comprendan las causas y consecuencias del engagement en el trabajo en el ámbito de la administración pública, ayudando a orientar la proposición de intervenciones en políticas públicas y prácticas de gestión de personas en las organizaciones públicas.

Palabras Clave: compromiso en el trabajo, antecedentes y resultados, sector público brasileño, agenda de investigación.

\section{INTRODUÇÃO}

O engajamento no trabalho tem sido alvo de debate entre acadêmicos e profissionais dos campos da psicologia, sociologia e da saúde nas últimas décadas (Shuck, 2011). Na administração, o tema também tem ganhado relevância, tendo se tornado um dos conceitos mais significativos nos últimos anos (Crawford, Rich, Buckman, \& Bergeron, 2014).

A temática ganhou escala na literatura mundial na década de 2010 (Fletcher, Bailey, Alfes, \& Madden, 2019). A razão para esta alavancagem recente dos estudos sobre engajamento no trabalho deve-se ao aumento das evidências sobre o constructo e sua relação positiva com desempenho individual no trabalho (Bailey, Madden, Alfes, \& Fletcher, 2017), satisfação de clientes, produtividade e lucro (Shuck, 2011). Além disso, altos níveis de engajamento são associados positivamente a comportamentos sociais e individuais, como cidadania e bem-estar individual (Christian, Garza \& Slaughter 2011; Hakanen \& Schaufeli 2012; Soane 2013).

Em levantamento na base de pesquisa Web of Science, em fevereiro de 2020, utilizando o termo "work engagement", foi possível observar o aumento do volume de publicações sobre o tema na última década (de 2011 a 2019), quando comparado com as décadas anteriores. A Figura 1 mostra a evolução histórica da quantidade de publicações sobre o tema nos últimos 40 anos. 


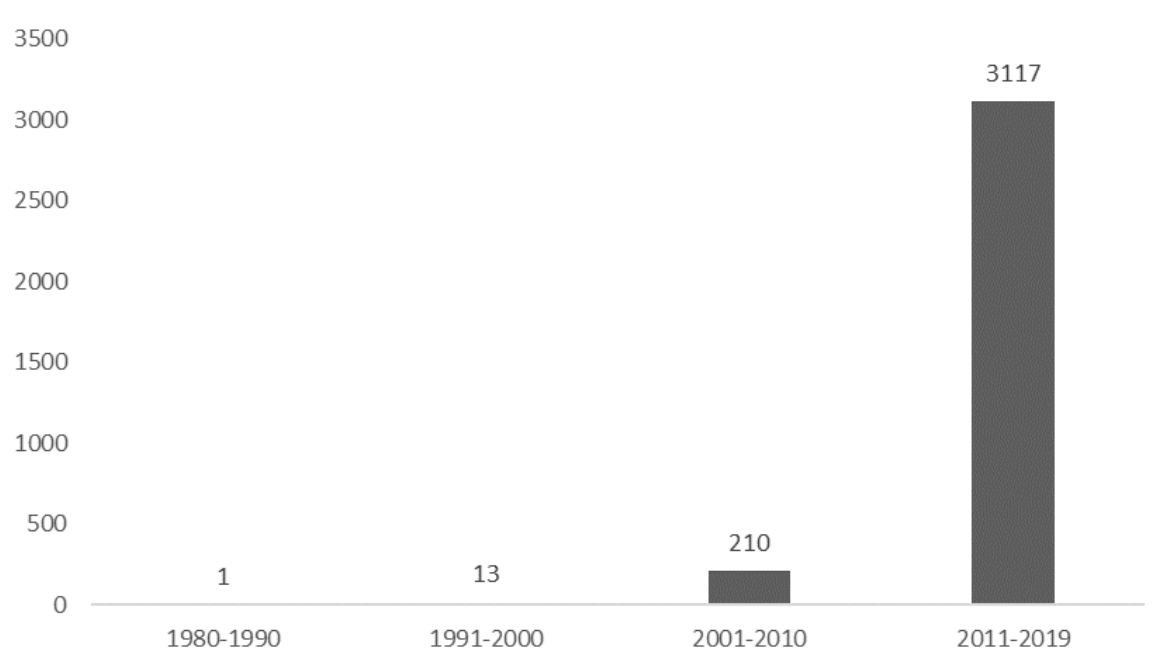

Figura 1 -Quantidade de estudos publicados na base Web of Science entre 1980 e 2019 sobre engajamento no trabalho (work engagement) Fonte: preparado pelos autores.

Estudos no setor privado têm demonstrado que engajamento no trabalho é um importante preditor de desempenho (Borst, Kruyen, Lako, \& de Vries, 2019). No setor público, embora receba menos atenção que no privado, já existem evidências de que engajamento no trabalho também é um importante preditor de desempenho em contextos específico (Borst et al., 2019). (Error 1: La referencia: 2019 está ligada a un elemento que ya no existe) (Error 2: La referencia: 2019 está ligada a un elemento que ya no existe) (Error 1: La referencia: Borst et al., 2019 está ligada a un elemento que ya no existe)

É possível afirmar que há diferenças significativas nos determinantes de engajamento quando se compara o setor privado com o público (Borst et al., 2019; Fletcher et al., 2019). As políticas e práticas para gerar engajamento nos dois setores não podem se dar da mesma forma (Fletcher et al., 2019): por exemplo, em geral, remuneração variável associa-se positivamente a desempenho no setor privado, o que parece não ocorrer no setor público (Bryson, Forth, \& Sotkes, 2017). (Error 3: La referencia: 2019 está ligada a un elemento que ya no existe) (Error 2: La referencia: Borst et al., 2019 está ligada a un elemento que ya no existe)

Ao se considerar essas diferenças como evidentes determinantes de engajamento no trabalho (Jenkins \& Delbridge, 2013), é preciso investir em estudos que levem em conta as características culturais e organizacionais nas quais os indivíduos trabalhadores se inserem. Assim, torna-se possível identificar fatores específicos de influência, bem como as maneiras pelas quais o engajamento é vivenciado (Fletcher et al., 2019). Em outras palavras, para compreender como ocorre o engajamento no trabalho em organizaçóes públicas, é necessário levar em consideração as características dos contextos social e organizacional, que são peculiares na administração pública e no país no qual se inserem.

A literatura de engajamento no trabalho no Brasil é escassa e limitada. Quando se trata de setor público, especificamente, ela é praticamente nula, conforme será apresentado e discutido. Considerando este vácuo na literatura nacional, o presente estudo tem como objetivo propor um marco analítico conceitual a respeito de engajamento no trabalho no setor público, gerando com isso uma ampla agenda de pesquisa para estudos futuros.

Para o alcance desse objetivo, inicialmente, foi realizado um apanhado conceitual sobre engajamento no trabalho e sua evolução desde o estudo seminal de William Kahn, publicado em 1990. Na sequência, o texto apresenta as teorias e achados sobre preditores, resultados e moderadores na literatura. $\mathrm{O}$ foco considerou especialmente as revisões sistemáticas de literatura que avançaram em proposições teóricas e meta-análises sobre o constructo no campo. Esse apanhado inicial torna-se relevante porque não há na literatura nacional 
ensaios teóricos que fazem essa discussão, muito menos estudos que realizaram uma análise abrangente e integradora do conhecimento produzido.

Este texto também apresenta um levantamento dos estudos sobre engajamento no trabalho realizados no contexto brasileiro, considerando os estudos realizados em organizações públicas e privadas em funcionamento no país. O apanhado explicita as lacunas de pesquisa do constructo no país. É possível perceber, na análise da produção nacional, que ainda são necessários estudos empíricos que envolvam antecedentes, moderadores e resultados do engajamento. Da mesma forma, faltam estudos que investiguem a influência do contexto social no engajamento.

A discussão sobre engajamento no trabalho no setor público é muito relevante, uma vez que a organização do trabalho, o foco e a trajetória dos trabalhadores no setor público diferenciam-se significativamente do setor privado. O risco de generalizar os achados no setor privado para o setor público é a adoção de políticas e práticas de gestão que não funcionam. Outro risco é que essas políticas tragam efeitos contrários ao previsto (Fletcher et al., 2019).

Outra contribuição deste ensaio se dá em relação aos gestores públicos. O Brasil busca avançar em políticas e práticas de gestão de pessoas, e estudos no campo podem servir para direcionar as melhores formas de atuação com vistas ao alcance de resultados de desempenho. Os estudos sobre preditores de engajamento no trabalho, em especial, prestam-se a essa finalidade. Embora sirvam como fonte de inspiração, o uso de resultados de outros contextos incorre no risco da adoção de recomendações que não são específicas o suficiente para pautar as políticas e práticas de gestão de recursos humanos no setor público de determinado país.

\section{Engajamento no Trabalho}

Bailey, Madden, Alfes e Fletcher (2017) apontam que a primeira definição para engajamento no trabalho foi desenvolvida por Kahn (1990), com o conceito de personal engagement. Passados 30 anos da publicação original de Kahn, não há ainda um consenso sobre o conceito de engajamento no trabalho (Bailey et al., 2017). No entanto, há autores que já se dispuseram a trabalhar na formulação de um conceito para o constructo. A Tabela 1 apresenta a trajetória de evolução do conceito engajamento no trabalho, com as principais denominações utilizadas. 
Tabela 1 - Evolução histórica do conceito de engajamento no trabalho

\begin{tabular}{|c|c|}
\hline Autores & Conceito \\
\hline Kahn (1990) & $\begin{array}{l}\text { "Personal engagement is the simultaneous employment and } \\
\text { expression of a person's 'preferred self' in task behaviours that } \\
\text { promote connections to work and to others, personal presence } \\
\text { (physical, cognitive and emotional) and active, full role performance" } \\
\text { (p. } 700 \text { ) }\end{array}$ \\
\hline $\begin{array}{l}\text { Maslach e Leiter } \\
(1997)\end{array}$ & $\begin{array}{l}\text { Engajamento é caracterizado por energia, envolvimento e eficácia, } \\
\text { que são considerados os opostos diretos das três dimensões da } \\
\text { sindrome de burnout exaustão, cinismo e falta de eficácia } \\
\text { profissional. Os trabalhadores engajados têm um senso de conexão } \\
\text { com suas atividades e se veem capazes de lidar completamente com } \\
\text { as demandas de seu trabalho. Conhecida como abordagem de } \\
\text { antitese ao burnout. }\end{array}$ \\
\hline $\begin{array}{l}\text { Schaufeli, } \\
\text { Salanova, } \\
\text { González- } \\
\text { Romá e Bakker } \\
\text { (2002) }\end{array}$ & $\begin{array}{l}\text { Engajamento é definido como um estado mental positivo, gratificante } \\
\text { e relacionado ao trabalho, caracterizado por vigor, dedicação e } \\
\text { absorção. Não se trata de um estado momentâneo e específico, refere- } \\
\text { se a um estado cognitivo afetivo mais persistente e difuso que não } \\
\text { está focado em nenhum objeto, evento, individuo ou comportamento } \\
\text { em particular. O vigor refere-se a altos niveis de energia e resiliência } \\
\text { mental durante o trabalho, a vontade de investir esforço no trabalho } \\
\text { e a persistência mesmo diante de dificuldades, enquanto a dedicação } \\
\text { é caracterizada por sentimentos de importância, inspiração, orgulho, } \\
\text { entusiasmo e desafio. Absorção refere-se a estar totalmente } \\
\text { concentrado e absorvido no trabalho. }\end{array}$ \\
\hline $\begin{array}{l}\text { Harter, } \\
\text { Schmidt, e } \\
\text { Hayes (2002) }\end{array}$ & $\begin{array}{l}\text { Engajamento é definido como envolvimento e satisfação do indivíduo } \\
\text { com entusiasmo pelo trabalho. }\end{array}$ \\
\hline Saks (2006) & $\begin{array}{l}\text { Engajamento no trabalho representa o quanto um individuo se vê, } \\
\text { psicologicamente, como membro de uma organização. Reflete até que } \\
\text { ponto um individuo está psicologicamente presente em uma função } \\
\text { organizacional específica. Engajamento organizacional é um } \\
\text { construto relacional e depende da relação de mão dupla entre } \\
\text { empregador e empregado que se estabelece a partir de trocas } \\
\text { econômicas e socioemocionais. As duas funçôes mais dominantes } \\
\text { para a maioria dos membros da organização são a função de } \\
\text { trabalho e a função de membro de uma organização. Portanto, o } \\
\text { modelo reconhece isso explicitamente, incluindo compromissos de } \\
\text { trabalho e organização. }\end{array}$ \\
\hline Shuck (2011) & $\begin{array}{l}\text { Engajamento no trabalho é visto como um estado mental positivo } \\
\text { cujos niveis são suscetiveis à influência de fatores contextuais e } \\
\text { interpessoais. }\end{array}$ \\
\hline $\begin{array}{l}\text { Truss, Shantz, } \\
\text { Soane, Alfes e } \\
\text { Delbridge } \\
\text { (2013) }\end{array}$ & $\begin{array}{l}\text { Engajamento no trabalho é visto (pela primeira vez) como um } \\
\text { subsistema de práticas de gestão estratégica de pessoas. }\end{array}$ \\
\hline
\end{tabular}

Fonte: preparado pelos autores com base em revisão da literatura.

Embora Kahn tenha apresentado um modelo psicológico teórico compreensivo para o engajamento no trabalho, ele não propôs a operacionalização do construto (Schaufeli, Salanova, González-Romá, \& Bakker, 2002). O conceito proposto por Maslach e Leiter (1997) avança nesse sentido. Ele permite a mensuração de engajamento a partir da ausência de burnout, sendo esse, segundo os autores, um estado de exaustão, cinismo e falta de eficácia profissional. Torna os dois conceitos antagônicos, de modo que a presença de um significa a ausência do outro, e vice-versa. Essa visão antagônica, aponta Bailey et al. (2017), começou a ser criticada, pois não possibilita a comparação entre os dois construtos, engajamento e burnout. 
No intuito de permitir a comparação entre engajamento e burnout, Schaufeli et al. (2002) avançaram para definições que permitissem a mensuração de ambos os conceitos de maneira independente. Amplamente conhecido como Grupo Utrecht, Schaufeli et al. (2002) desenvolveram uma escala de mensuração para engajamento no trabalho, a Utrecht Work Engagement Scale (UWES), que se tornou o instrumento mais utilizado nos estudos do campo em todo o mundo (Bailey et al., 2017).

Usando a abordagem da psicologia positiva, Harter et al. (2002) acrescentam satisfação como parte do conceito de engajamento. Harter e seus colaboradores, chamado de Grupo Gallup, também desenvolveram um instrumento próprio para mensuração do construto engajamento, denominado Gallup Work Audit (GWA), utilizado em diversas pesquisas do campo (Shuck, 2011).

Sack's (2006), por sua vez, foi o responsável pela ampliação do conceito de engajamento no trabalho a um patamar multinível. Ele propóe a diferenciação entre o engajamento no trabalho e o engajamento organizacional. Tendo como base a Social Exchange Theory, Saks (2006) amplia o conceito para além da usual visão individual, utilizando uma perspectiva relacional. Em uma tentativa de unir conceitos, Suck (2011) propôs a visão do engajamento como um estado positivo da mente, que sofre influência do contexto e dos fatores interpessoais.

O trabalho de Truss et al. (2013) aponta a necessidade de acadêmicos e practitioners da chamada gestão estratégica de pessoas utilizarem o conceito de engajamento para pautar as políticas e práticas de gestão de pessoas nas organizações. Diante das evidências empíricas da relação entre engajamento e desempenho (Bailey et al.,2019; Borst et al., 2019), o campo de gestão de pessoas pode atuar na promoção do engajamento. Truss et al. (2013), contudo, ressaltam que não é absoluta a visão de que o engajamento pode ser invariavelmente um cenário de "ganha-ganha" para funcionários e empregadores. Segundo esses autores, há de se considerar as relações de poder e restrições contextuais vivenciadas no processo de promoção de engajamento.

$\mathrm{O}$ que diferencia engajamento de outros conceitos encontrados no campo do comportamento organizacional? Nas análises da evolução do conceito de engajamento no trabalho, parte das críticas deve-se à proximidade com outros conceitos, como satisfação com o trabalho e comprometimento organizacional. No entanto, a diferença entre os conceitos é explícita. Enquanto indivíduos engajados vivenciam uma conexão com seu trabalho em múltiplos níveis - físico, emocional e cognitivo (Christian et al., 2011) —, satisfação no trabalho, por sua vez, diz respeito ao julgamento positivo ou negativo sobre o trabalho ou sobre uma situação no trabalho (Weiss, 2002). As definições operacionais dos dois constructos, que permitiram o desenho de escalas de mensuração, deixam clara a diferença entre satisfação e engajamento. Satisfação envolve condições de trabalho (como, por exemplo, "Eu gosto do meu pagamento"), enquanto engajamento se refere a experiências individuais resultantes do trabalho (como, por exemplo, "Sinto-me com vigor quando trabalho") (Christian et al., 2011).

Em relação ao conceito de comprometimento no trabalho, a diferenciação com o conceito de engajamento é menos evidente. A literatura aponta três tipos de comprometimento no trabalho: a) afetivo, b) de continuidade e c) normativo. O comprometimento afetivo refere-se ao "apego emocional do empregado, identificação e envolvimento na organização", enquanto o compromisso de continuidade consiste na "conscientização dos custos associados à saída da organização" (Meyer \& Allen, 1991, p. 67). Já o compromisso normativo representa uma obrigação percebida de permanecer na organização (Meyer, Stanley, Herscovitch, \& Topolnytsky, 2002).

Para Robinson, Perryman e Hayday (2004), o conceito de engajamento guarda uma relação próxima com o conceito de comprometimento, especialmente o chamado comprometimento afetivo. Macey e Schneider (2008), por sua vez, afirmam que comprometimento é uma das facetas de engajamento, mas não é suficiente para sua geração. O que diferencia os dois conceitos é que comprometimento consiste na atitude e apego dos indivíduos em relação à sua organização, e não ao trabalho em si, como ocorre com engajamento (Saks, 2006; Christian et al., 2011). Engajamento não é atitude, mas o grau em que um indivíduo está atento e absorvido no desempenho de seu trabalho (Saks, 2006). 
Christian et al. (2011), em uma meta-análise da literatura, demonstraram que engajamento, diferentemente dos demais conceitos, tem maior valor preditivo em relação a desempenho no trabalho. Os autores apontam que, a despeito de estarem satisfeitos e comprometidos com suas organizações, indivíduos podem não possuir recursos pessoais para persistir em momentos de dificuldade (vigor) ou de concentração (absorção). Segundo esses mesmos autores, essas características são típicas de pessoas engajadas.

$\mathrm{O}$ avanço recente dos estudos sobre engajamento também se tem debruçado em estabelecer modelos teóricos e testá-los, a fim de estabelecer a relação do construto com outras variáveis, o que será abordado na próxima seção.

\section{TEORIAS SOBRE ANTECEDENTES E RESULTADOS DO ENGAJAMENTO NO TRABALHO}

Os constructos que explicam os diferentes comportamentos no trabalho costumam pautar-se em abordagens teóricas consolidadas. No caso de engajamento no trabalho, conforme os achados de Bailey et al. (2017), diversas teorias têm pautado os estudos. A primeira delas, presente na maioria das pesquisas do campo, é a chamada job demands-resources theory (JD-R), ou teoria de demandas-recursos no trabalho.

Considerada como uma extensão do chamado job-demands model e inspirada nas teorias de job design e job stress, a teoria JD-R foi elaborada em 2001 por Demerouti, Bakker, Nachreiner e Schaufeli, e aprimorada 15 anos depois por Bakker e Demerouti (2016). A JD-R busca explicar como as demandas e recursos (pessoais e organizacionais) nos ambientes de trabalho desempenham um efeito multiplicador de estresse e motivação no trabalho (Bakker \& Demerouti, 2016). Por um lado, os recursos geram energia entre os trabalhadores e promovem motivação, engajamento, comprometimento, que, por sua vez, produzem resultados positivos, como altos níveis de bem-estar e desempenho (Schaufeli, 2014). As demandas, por outro lado, exigem que as pessoas gastem esforços adicionais que, com o tempo, podem causar a manifestação da síndrome do esgotamento profissional, como ansiedade e adoecimento. Como consequência, isso gera resultados negativos de desempenho (Bakker \& Demerouti, 2016).

A JD-R busca explicar qual o ponto ótimo entre recursos no trabalho e (ou) pessoais versus volume de demandas no qual se alcança maior engajamento e produtividade (Bailey et al., 2017). Nessa teoria, o engajamento no trabalho é apontado como mediador entre recursos/demandas e o desempenho no trabalho, funcionando como ativador de satisfação com a atividade profissional (Schaufeli \& Bakker, 2004; Bakker \& Demerouti, 2016). Essa relação pode ser observada na Figura 2. 
Figura 2 - Modelo job-demands resources

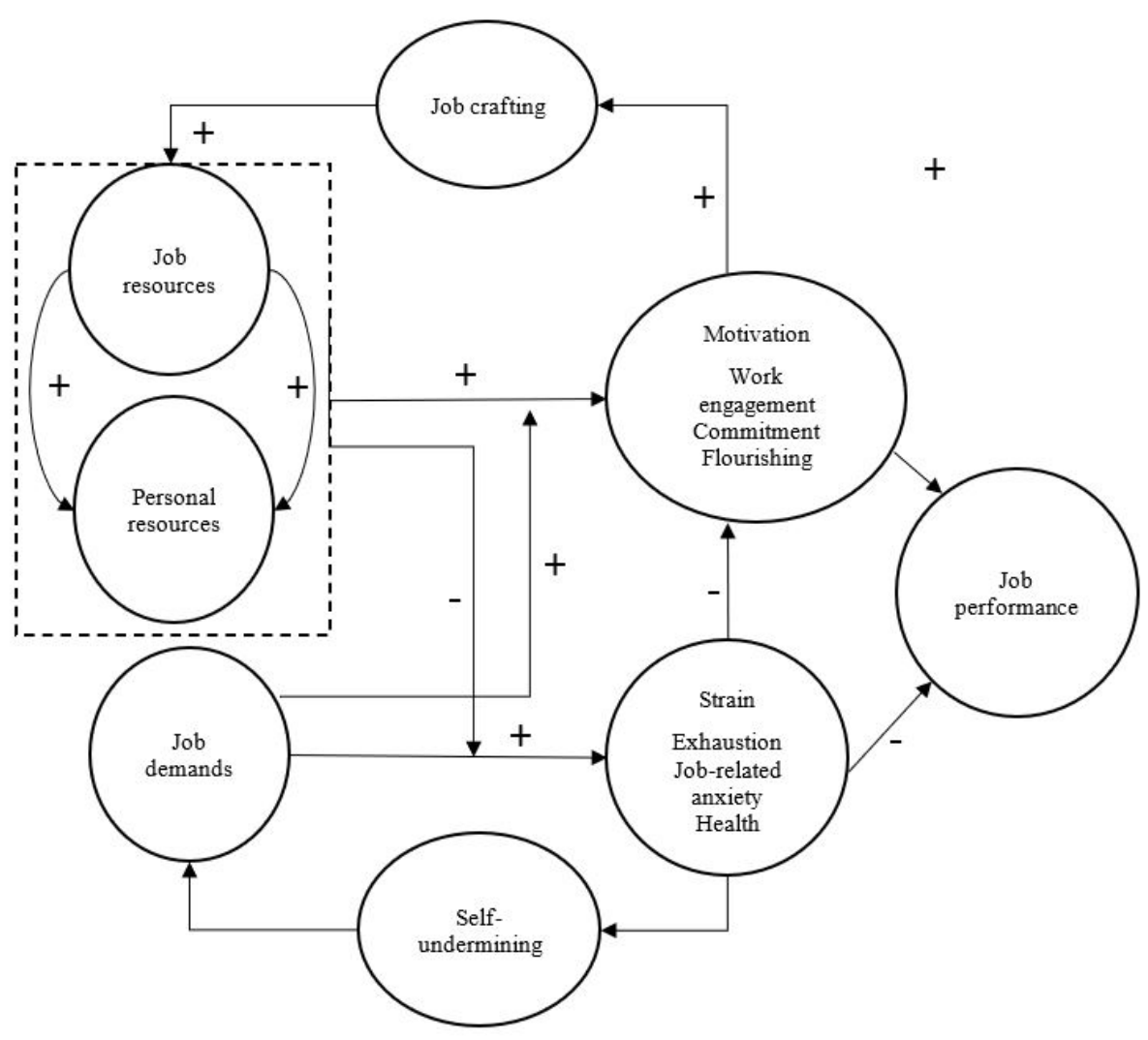

Fonte: Bakker e Demerouti (2016, p. 3).

Outras abordagens teóricas utilizadas para explicar engajamento no trabalho, embora em menor quantidade de estudos publicados quando comparada à JD-R, são indicadas por Bailey et al. (2017): social exchange theory (SET), teoria de conservação de recursos, e broaden-and-build theory. A social exchange theory (SET) pressupõe que os comportamentos são contingentes às reações recompensadoras (econômicas e sociais) de outras pessoas (Cropanzano \& Mitchell, 2005). Nas relações de trabalho, os empregados que percebem que estão sendo bem tratados e avaliados pelo empregador têm maior probabilidade de exercer esforços em nome desse empregador, por meio de níveis elevados de engajamento (Alfes, Shantz, Truss, \& Soane, 2013a).

A teoria de conservação de recursos baseia-se na premissa de que os indivíduos buscam adquirir e preservar recursos valiosos, que podem ser recursos pessoais, energéticos, sociais ou materiais (Bailey et al., 2017). De acordo com essa visão, a provisão de recursos pode ser particularmente importante na elevação dos níveis de engajamento entre aqueles que estão enfrentando altos níveis de demanda, uma vez que os recursos amortecem seus efeitos potencialmente negativos (Bakker, Hakanen, Demerouti, \& Xanthopoulou, 2007).

Por último, na broaden-and-build theory, o engajamento é mais provável que ocorra quando os indivíduos experimentam resultados positivos ao invés de emoçóes negativas, pois elas criam o espaço para uma gama mais ampla de repertórios de pensamento-ação (Fredrickson, 2001). Essa teoria, segundo Bailey et al. (2017), argumenta que indivíduos que experimentam emoções positivas são capazes de recorrer a uma gama mais ampla de respostas comportamentais e são mais propensos a se engajar no trabalho.

A partir da multiplicação de estudos no tema, autores têm buscado sintetizar modelos preditivos e de resultados a partir de variáveis preconizadas em textos teóricos ou estudos empíricos específicos no tema. Um dos primeiros trabalhos nesse sentido foi realizado por Saks (2006), que testou um modelo de antecedentes 
e consequências de engajamento (no trabalho e organizacional) com base na SET. A Figura 3 apresenta o modelo testado por Saks (2006).

Figura 3 -Modelo de antecedentes e consequentes de engajamento no trabalho

\begin{tabular}{|c|c|c|}
\hline Antecedents & & Consequences \\
\hline Job characteristics & Employee Engagement & Job satisfaction \\
\hline $\begin{array}{l}\text { Perceived supervisor support } \\
\text { Rewards and recognition } \\
\text { Procedural justice } \\
\text { Distributive justice }\end{array}$ & $\begin{array}{l}\text { Job engagement } \\
\text { Organizational engagement }\end{array}$ & $\begin{array}{l}\text { commitment } \\
\text { Intention to quit } \\
\text { Organizational } \\
\text { citizenship behaviour }\end{array}$ \\
\hline
\end{tabular}

Fonte: Sacks (2006, p. 604).

Para Saks (2006), os conceitos de engajamento no trabalho e engajamento organizacional são diferentes, embora relacionados. Ambos explicam uma variância significativa na satisfação no trabalho, no comprometimento organizacional, na intenção de permanecer na organização e no comportamento organizacional cidadão. $\mathrm{O}$ autor também identificou que a percepção de suporte organizacional é preditor de ambos engajamentos. Características do trabalho é preditor de engajamento no trabalho e justiça processual atua como preditor de engajamento organizacional. Os achados também indicam que ambas as formas de engajamento estão relacionadas a atitudes, intenções e comportamentos no trabalho. Além disso, engajamento funciona como variável mediadora entre os antecedentes e resultados do modelo (Saks, 2006).

Outro estudo que avançou no entendimento das relações de engajamento com variáveis preditoras e de resultados foi a meta-análise realizada por Crawford, Lepine e Rich (2010), com foco em testagem da relação da teoria job demands and resources e engajamento e burnout. Os autores demonstraram, conforme modelo da Figura 4, que demandas desafiadoras e recursos possuem relação positiva com engajamento. Por outro lado, demandas vistas como obstáculos têm relação negativa. Os autores ressaltam que é a percepção do trabalhador que determina se uma demanda será vista como desafio ou como obstáculo. 
Figura 4 - Relação entre demandas, recursos, burnout e engajamento

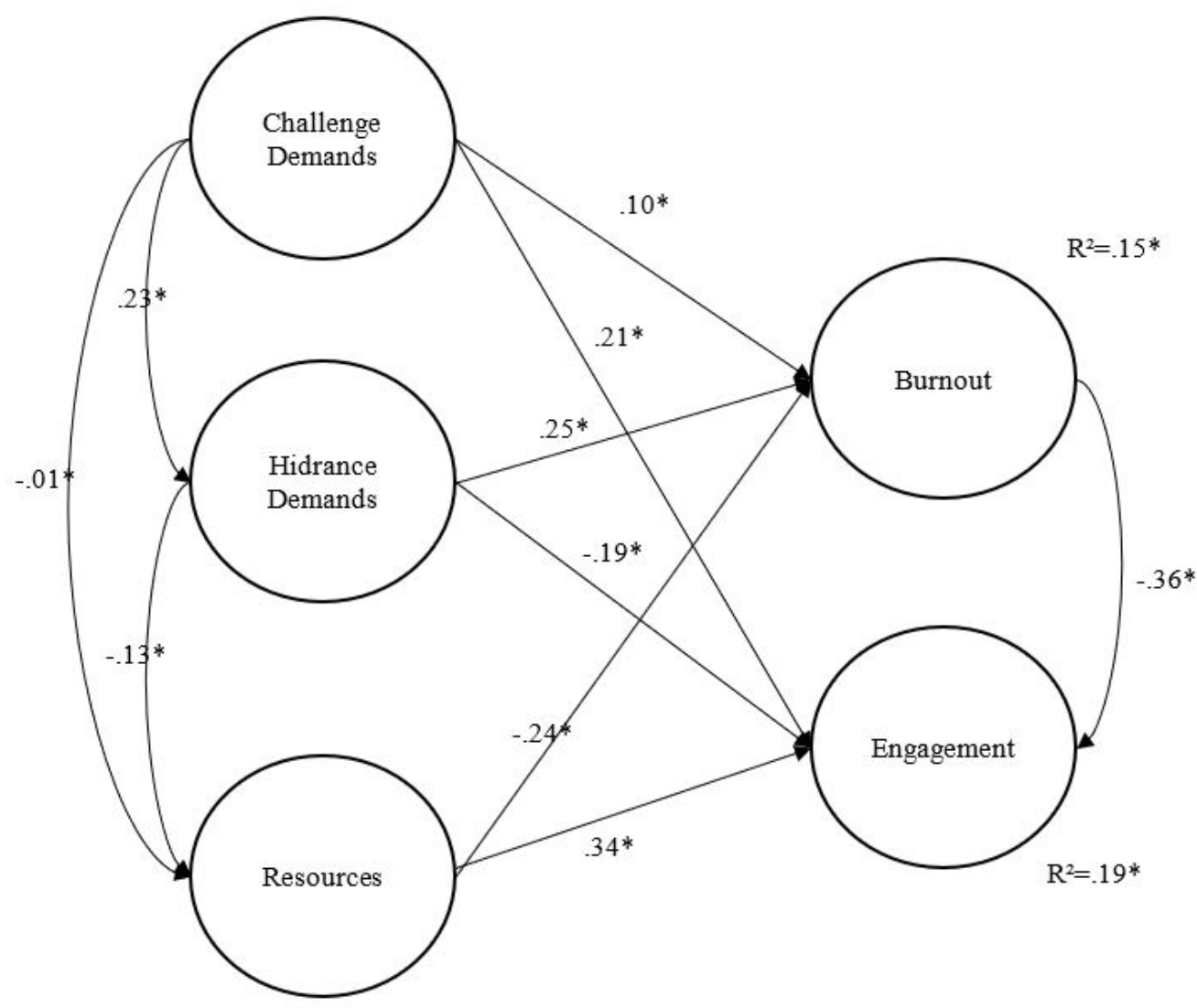

Fonte: Crawford, Lepine e Rich (2010, p.841).

Parece haver consenso de que as demandas de trabalho percebidas pelos funcionários como desafiadoras ou potencialmente promotoras de seu crescimento pessoal exibem resultados positivos enquanto as demandas de trabalho percebidas como obstáculos exibem resultados negativos (Ventura, Salanova, \& Llorens, 2015). As pessoas com alto grau de auto-eficácia costumam ver as demandam mais como desafios (Llorens, Schaufeli, Bakker, \& Salanova, 2007; Salanova, Llorens, \& Schaufeli, 2011).

Outro trabalho importante da literatura do campo é o de Peccei (2013), que propõe um framework para análise de antecedentes e resultados de engajamento no trabalho a partir da análise sistemáticas de estudos. Esse framework, apresentado na Figura 5, estabelece uma relação entre resultados e antecedentes de engajamento no trabalho e provoca para a necessidade de ampliação de estudos empíricos na temática. 
Figura 5 - Framework de antecedentes e resultados de engajamento no trabalho

\begin{tabular}{|l|l|l|}
\hline \multicolumn{1}{|c|}{ Antecedents } \\
Job Resources \\
Challenge Demands \\
Individual Differences \\
Non-work Factors
\end{tabular} \mid $\begin{aligned} & \text { Outcomes } \\
& \text { Work Engagement } \\
& \text { Attitudinal } \\
& \text { Behavioural } \\
& \text { Contextual Performance } \\
& \text { Health } \\
& \text { Turnover Intention }\end{aligned}$

Fonte: Peccei (2013, p. 337).

Além de recursos, demandas desafiadoras e demandas obstáculo como antecedentes de engajamento, o modelo de Peccei (2013) acrescenta as diferenças individuais e os fatores fora do trabalho entre os preditores. A visão de engajamento é vista como um componente atitudinal (querer fazer) que se traduz em comportamentos no trabalho. Entre os resultados, o modelo apresenta não apenas o desempenho (na tarefa e contextual), mas também saúde e intenção de sair da organização como consequências de engajamento.

O estudo de Bailey et al. (2017) avança significativamente em relação ao de Peccei (2013). Os autores realizaram uma análise pormenorizada de 214 artigos sobre engajamento no trabalho e identificaram um primeiro detalhamento amplo no sentido de relatar antecedentes e resultados de engajamento no trabalho. O estudo também apontou que algumas intervenções, como treinamento e desenvolvimento e novas formas de trabalho, têm ampliado os níveis de engajamento nas organizações.

Entre os antecedentes de engajamento no trabalho, o estudo de Bailey et al. (2017) apontou como principais: i) estados psicológicos individuais como auto eficácia, resiliência e recursos pessoais; ii) fatores relacionados ao design de trabalho no contexto da JD-R como suporte da chefia imediata, suporte dos pares, feedback e autonomia; iii) liderança percebida e gestão como liderança transformacional, confiança no gestor/líder e liderança autêntica; e iv) percepções individuais sobre a organização/equipe de trabalho como suporte organizacional, contratos relacionais, identificação com a organização, nível de engajamento da equipe, clima e comunicação.

Quanto aos resultados do engajamento, duas evidências são apontadas nos achados de Bailey et al. (2017). A primeira, relacionada a desempenho, aponta que o engajamento se relaciona positivamente a desempenho em diferentes níveis - dos indivíduos, das equipes, da lealdade dos clientes e da qualidade do cuidado. Além disso, desempenhos para além da tarefa também são associados a engajamento como comportamento cidadão e inovação. A segunda evidência diz respeito à moral, como percepção de bem-estar e saúde no trabalho, e às atitudes relacionadas ao trabalho, como rotatividade e intenção de permanecer na organização (Bailey et al., 2017).

Diversos autores (Peccei, 2013; Bailey et al., 2017) concordam que ainda há um vasto campo a ser explorado nos estudos de engajamento no trabalho. Há limitações claras nas próprias definições e estratégias de mensuração de engajamento, ainda mais considerando que a maioria dos estudos utiliza a mesma escala, a UWES (Bailey et al., 2017; Pecci, 2013). A diferenciação entre engajamento no trabalho e engajamento organizacional não é clara e há escassez de estudos analisando os dois conceitos de forma comparada. A visão 
de engajamento como uma prática de gestão, proposta por Truss et al. (2013), por exemplo, é um campo ainda pouco explorado na literatura do campo, e, portanto, com um rico potencial (Bailey et al., 2013).

Um ponto também apontado pela literatura é o fato de que, embora não exista um consenso conceitual, as evidências são amplas em reconhecer que fatores contextuais são determinantes (Jenkins \& Delbridge, 2013). Uma das críticas dos estudiosos sobre engajamento no trabalho é justamente a visão com foco individual e "psicologizada" (Purcell, 2014). Além de ignorar as questões contextuais, essa visão normativa/prescritiva ignora o processo decisório que envolve a escolha do servidor em seu ambiente de trabalho e o que o direciona.

O entendimento de engajamento na literatura, em geral, não costuma considerar fatores contextuais em suas análises (Purcell, 2014), embora autores reconheçam sua relevância (Purcell, 2014; Valentin, 2014). Entendendo que a perspectiva contextual é determinante para o engajamento (Jenkins \& Delbridge, 2013), é possível afirmar que estudos em determinado país devem pautar-se, preferencialmente, em pesquisas já realizadas naquele contexto específico. Nesse sentido, considerando que este ensaio pretende estabelecer uma agenda de pesquisa no contexto brasileiro, a seção seguinte traz uma revisão com os avanços e lacunas na literatura nacional.

\section{Estudos de Engajamento no Trabalho no Brasil}

Os estudos sobre engajamento no trabalho no Brasil ainda são escassos. Na busca realizada na base Web of Science com os termos "work engagement" ou "employee engagement" e "Brazil" foram encontrados apenas seis estudos realizados no contexto brasileiro que estudaram ou tiveram engajamento no trabalho como variável no estudo. Em uma busca na base científica Scientific Electronic Library Online .Scielo), realizada em 16 de abril de 2020, com os termos "engajamento no trabalho", "work engagement" e "employee engagement", foram encontrados apenas 21 artigos.

Três estudos dispuseram-se a validar a escala de mensuração de Utrecht (UWES) no contexto brasileiro. O primeiro, conduzido por Vazquez, Magnan, Pacico, Hutz e Schaufeli (2015), realizou validação semântica e de conteúdo dos 17 itens da escala completa e dos 9 itens da versão reduzida. Em linha similar, Ferreira et al. (2016) validaram a versão reduzida da escala de Utrecht no Brasil (UWES-9) e recomendaram o uso da mesma em estrutura unidimensional para avaliação de engajamento no trabalho no contexto nacional. O terceiro, realizado por Sinval, Pasian, Queirós e Maroco (2018), validou a versão em português com trabalhadores no Brasil e Portugal, e os achados sobre a UWES-9 foram similares nos dois países.

Sobre os achados de preditores e resultados, as evidências são escassas e alguns estudos foram realizados em contexto muitos específicos. A despeito dessas especificidades, os estudos trazem algumas evidências sobre variáveis preditivas testadas em trabalhadores brasileiros. Entre os preditores positivos estão a articulação entre valores pessoais e valores organizacionais (Andrade, 2019), práticas gerenciais e liderança (Novaes, Ferreira, \& Garbado-Martins, 2019; Andrade, 2019; Silva, Ferreira, \& Valentini, 2019; Oliveira \& Rocha, 2017), participação na tomada de decisão (Chinelato, Ferreira, \& Valentini, 2019), percepção de justiça no trabalho - distributiva e interpessoal (Andrade, 2019; Oliveira \& Ferreira, 2016) —, resiliência (Oliveira \& Ferreira, 2016), avaliação autorreferente, percepção de práticas de recursos humanos (Oliveira \& Rocha, 2017; Chambel \& Farina, 2015), boas relações no ambiente de trabalho (Santos, Castanheira, Chambel, Amarante, \& Costa, 2017), autenticidade (Reis, Trullen, \& Story, 2016), idade e experiência (Silva et al., 2020) e redesenho do trabalho (Chinelato, Ferreira, \& Valentini, 2015).

Dentre os preditores negativos, foram identificados apenas o estresse ocupacional (Cordioli et al., 2019) e a ambiguidade de papel (Chinelato et al., 2019). Tanto nos resultados nacionais quanto nos internacionais a agenda de variáveis com relação negativa com engajamento é pouco explorada. No entanto, as práticas de gestão podem beneficiar-se da entrada de variáveis positivas tanto quanto da retirada de preditores negativos.

Estudo no Brasil com variáveis moderadoras e resultados de engajamento são ainda mais escassos. Apenas um estudo trabalhou com a presença de uma variável moderadora entre valores e engajamento no 
trabalho/satisfação no trabalho (Andrade, 2019). Nos demais estudos não houve identificação de variáveis moderadoras.

Apenas dois dos 27 estudos encontrados trataram de resultados de engajamento no trabalho. $\mathrm{O}$ artigo de Farina, Rodrigues e Hutz (2018) associa engajamento ao aumento de desempenho nos negócios, aumento do desempenho do trabalhador e da satisfação de vida. Oliveira e Rocha (2017), por sua vez, encontraram relação entre engajamento no trabalho e redução da intenção de rotatividade.

A despeito de avanços apresentados nesses estudos nacionais, ainda não há um volume de estudos que permita delimitar o comportamento do constructo no país. Além disso, as análises contextuais que determinam engajamento não se restringem ao país de atuação dos trabalhadores. A diferença entre organizações públicas e privadas foi raramente considerada pela literatura específica, inclusive no contexto internacional (Fletcher et al., 2019). Como será abordado na próxima seção, diferenciar setor público e privado se justifica, uma vez que o objeto de atuação dos dois setores, as formas de organização do trabalho, e os determinantes motivacionais se diferenciam e possuem trajetórias diferentes e isso tende a se refletir nos determinantes e resultados de engajamento, conforme será apresentado a seguir.

\section{Estudos de Engajamento no trabalho no Setor Público}

No setor público, as práticas de gestão de pessoas diferenciam-se do setor privado e guardam especificidades contextuais próprias (Harel \& Tzafrir, 2002), o que exige estudos específicos sobre seus efeitos. A própria origem da forma de organização de pessoal torna as trajetórias dessas práticas distintas. Enquanto no setor privado a origem se dá na revolução industrial e se inspira nos trabalhos de Taylor (1856-1915) e Fayol (1841-1925) (Legge, 2005), na administração pública as práticas surgem da necessidade de superação de um modelo patrimonialista de Estado e inspiram-se nos trabalhos seminais de Max Weber.

Ao tratar a temática de engajamento no setor público é fundamental, previamente, contextualizar sua relação com a tradicional Public Service Motivation (PSM), teoria que avançou enormemente desde o texto seminal de Perry e Wise (1990). No campo da economia, a PSM é vista como uma especificação do altruísmo, ou seja, uma disposição dos indivíduos de se envolverem em comportamentos para o bem dos outros, sem benefícios recíprocos para si mesmos (Perry \& Vandenabeele, 2015). Pesquisadores da área do comportamento organizacional (Carpenter, Doverspike, \& Miguel, 2012) e da gestão estratégica de pessoas (Wright \& Grant, 2010) também têm usado a PSM em seus estudos. Na ciência política, a PSM tem sido amplamente utilizada em análises de comportamento agente-principal (Gailmard, 2010).

Nos apontamentos de Perry e Wise (1990), a motivação para o serviço público estimula os indivíduos a buscarem empregos em organizações públicas. Além disso, a motivação está positivamente relacionada ao desempenho das organizações públicas, o que torna as organizações públicas menos dependentes de incentivos extrínsecos em sua gestão.

Após uma ampla análise de literatura, Perry, Hondeghem e Wise (2010) definiram PSM como "a particular form of altruism or prosocial motivation that is animated by specific dispositions and values arising from public institutions and missions" (p. 682). Apesar das teorias de escolha racional baseadas em suposições de comportamento de interesse próprio terem tido uma influência importante na teoria e na prática da administração pública nas últimas décadas, o PSM oferece uma perspectiva alternativa para pesquisa e prática em gestão pública. Isso por que, segundo a PSM, os indivíduos são orientados a agir com o objetivo de fazer o bem aos outros e à sociedade (Perry, Hondeghem, \& Wise, 2010).

Um dos aspectos centrais da PSM é que, desde os postulados iniciais de Perry e Wise (1990), ela é considerada um dos principais preditores para desempenho no setor público. No entanto, o avanço dos estudos demandou um aumento de análise das variáveis intermediárias, mediando a relação entre PSM e desempenho (Perry et al., 2010). Fletcher et al. (2019) demonstraram que PSM é uma das chaves motivadoras quando se trata de servidores públicos e uma teoria de engajamento no setor público deve considerar essa 
questão. Há evidências de que a PSM é um dos antecedentes de engajamento no trabalho (Borst, 2018; Cooke, Brant, \& Woods, 2019).

Fletcher et al. (2019) fizeram uma ampla revisão da literatura de antecedentes, resultados e moderadores de engajamento no contexto das organizações públicas, analisando 188 estudos publicados desde 1990 sobre a temática. Com base nos achados, esses mesmos autores construíram um mapa de antecedentes, resultados e contingência/moderadores contextuais, conforme apresentado na Figura 6.

Figura 6 - Mapa de antecedentes, resultados e contingências/moderadores de engajamento

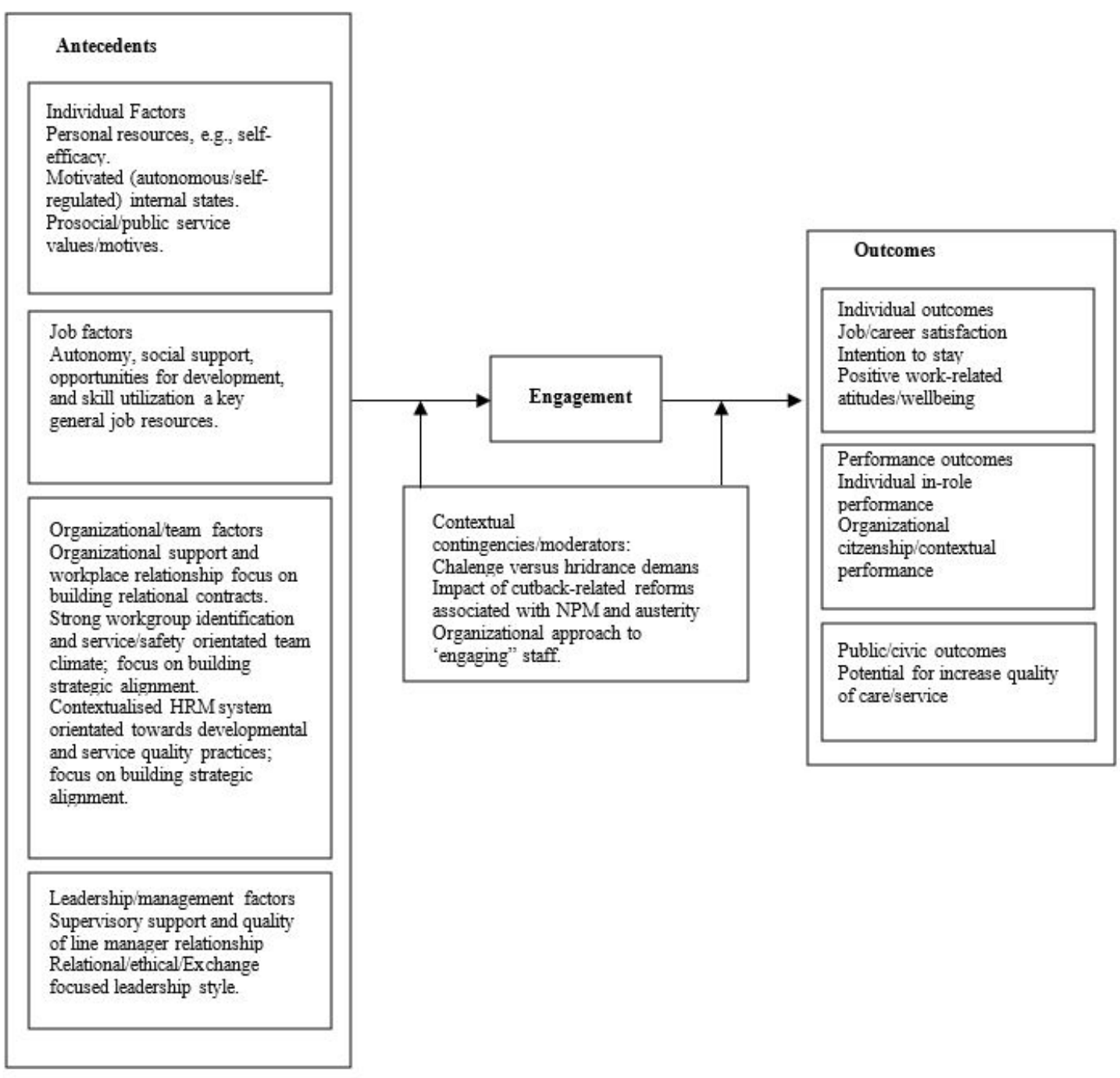

Fonte: Fletcher et al. (2019 p. 13).

A análise produzida por Fletcher et al. (2019) diferencia-se dos modelos anteriores em alguns aspectos, por exemplo, o fato de as dimensões contextuais aparecem como moderadoras do engajamento e não preditivas. Um ponto relevante para o setor público é a questão do pró-social, que aparece como antecedente importante. O mesmo não ocorre com trabalhadores do setor privado. Essas questões, contudo, aparecem fortemente nos chamados burocratas de nível de rua (enfermeiras, policiais, professores etc.), mas o estudo não especifica, explicitamente, a situação dos servidores do núcleo central de governo, que têm menos contato direto com o cidadão.

É saliente ressaltar que a maior parte dos estudos encontrados por Fletcher et al. (2019) foi desenvolvido na Europa. Segundo os autores, posições ideológicas de como o governo deve servir aos interesses públicos pode 
afetar os preditores de engajamento. Os autores perceberam na análise dos estudos que, a depender do país e do setor de governo, o engajamento entre servidores públicos é diferente. Por isso, o desenho de soluções de gestão de pessoas no contexto de um país deve advir de estudos realizados no contexto específico.

Uma vez que as variáveis culturais, sócio-políticas e organizacionais podem afetar a relação entre antecedentes e resultados do engajamento de servidores públicos, é problemático fazer generalizações com base em resultados encontrados em outros contextos diferentes da administração pública brasileira. $\mathrm{O}$ uso de resultados de outros contextos pode incentivar a adoção de recomendações que não são específicas o suficiente para pautar as políticas e práticas de gestão de pessoas no setor público de determinado país (Fletcher et al., 2019).

Considerando que as diferenças contextuais são significativas para nível de engajamento, torna-se necessária a proposição de um modelo considerando características típicas do contexto brasileiro. $\mathrm{Na}$ análise da literatura nacional, apenas dois estudos com foco específico em setor público foram encontrados: o estudo de Andrade (2019), que fez uma análise comparada entre o serviço público brasileiro e o português; e o estudo de Jackson (2015), que se trata de uma revisão de literatura nacional sobre ergonomia da atividade e seu impacto no engajamento no trabalho no setor público brasileiro. Embora relevantes, esses estudos não enfrentam questões básicas para o engajamento no trabalho, como variáveis contextuais, organizacionais e institucionais. Na seção seguinte serão abordados possíveis caminhos para uma agenda de pesquisa sobre engajamento no trabalho no setor público brasileiro.

\section{Marco Analítico, Agenda e Proposições de Pesquisa}

O grande interesse pela temática do engajamento no trabalho não deixa dúvidas sobre a relevância que o tema tem adquirido na literatura mundial. Essa seção apresenta uma proposta de marco analítico e algumas possibilidades de agenda de pesquisa que podem contribuir para ampliação do conhecimento a respeito do tema e pautar estratégias e decisões em relação às práticas gerenciais que ampliem o engajamento no trabalho no setor público. Uma síntese das reflexões é apresentada em forma de proposições ao longo da seção.

Seguindo os achados do modelo de Fletcher et al. (2019), exposto na Figura 6, propomos um marco analítico direcionador para estudos de engajamento no trabalho no setor público brasileiro. A Figura 7 apresenta um modelo de múltiplos níveis e relações que podem ser identificadas e estudadas no contexto público nacional, a fim de construir um modelo teórico mais amplo. 
Figura 7 - Marco analítico proposto para engajamento no trabalho no setor público

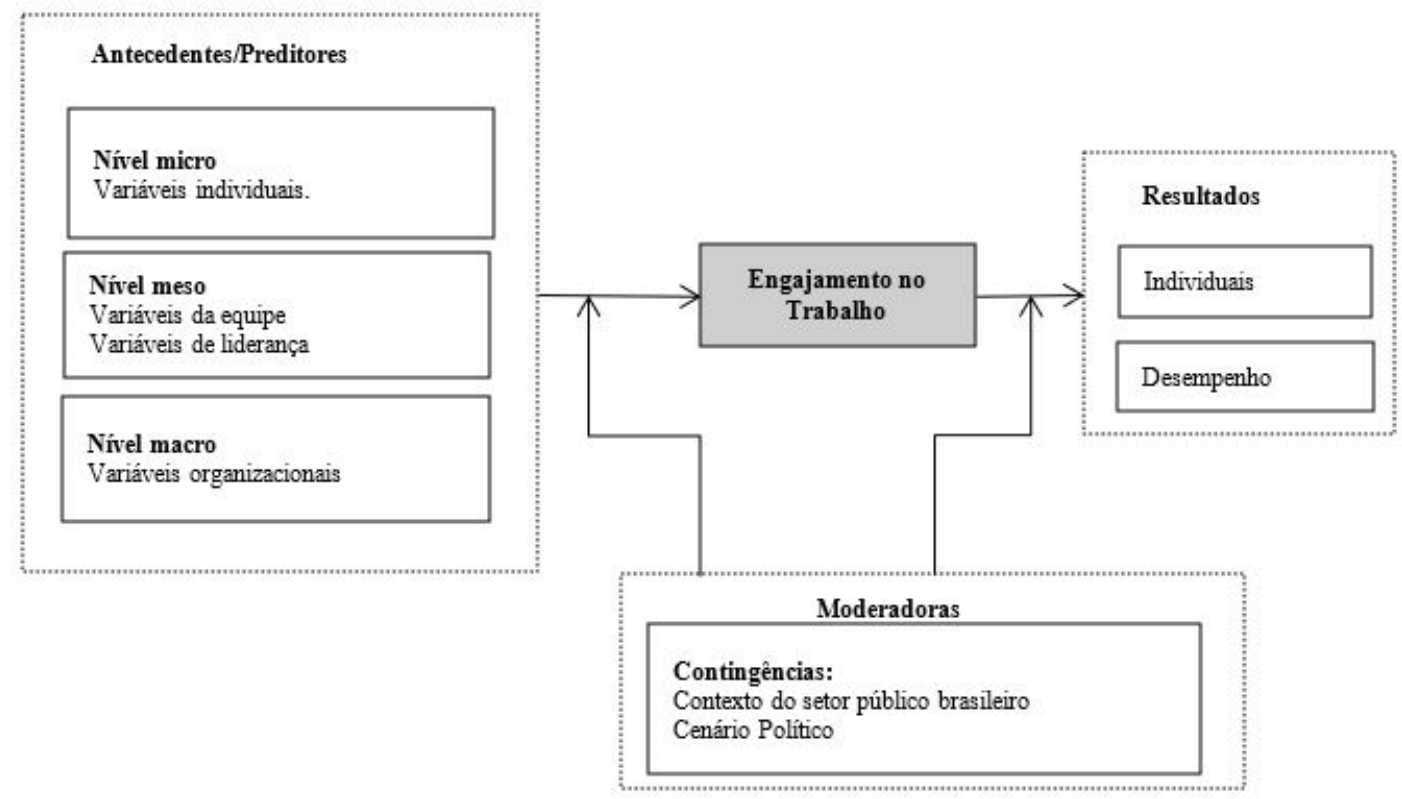

Fonte: elaborado pelos autores.

O marco analítico proposto é multinível, ou seja, o modelo trata de variáveis antecedentes explicativas do engajamento situadas nos níveis individual (micro), de grupo (meso) e organizacional (macro). Engajamento no trabalho é entendido também como antecedente de resultados individuais e organizacionais (desempenho). Por fim, o marco analítico traz variáveis moderadoras (fatores contingenciais) da relação entre antecedentes e resultados.

O marco analítico proposto é amplo e não especifica as diversas possibilidades de variáveis em cada um dos níveis, isso porque, considerando a escassez de estudos sobre o construto no setor público brasileiro, entendese que a agenda deve se debruçar, inicialmente, em estudos exploratórios. A agenda nacional precisa testar, de forma ampla, as variáveis já aferidas em contextos internacionais. Identificar de que forma as variáveis nos diferentes níveis se comportam e o que aparece de forma mais evidente no contexto nacional seria relevante. É provável que existam variáveis típicas da cultura organizacional do serviço público brasileiro, ou variáveis do contexto político-institucional mais amplo, que possam ser determinantes importantes do engajamento. Os valores associados ao serviço público são diferentes em todo o mundo, portanto, é provável que os significados de engajamento também variem e sejam mais institucionalizados em alguns países do que em outros (Perry et al., 2010).

Os estudos exploratórios justificam-se ainda pela possibilidade de existirem variáveis específicas, não amplamente identificadas na literatura internacional, que exerçam influência no engajamento, ou seja, são variáveis específicas do contexto de análise que determinam o engajamento. Apenas um levantamento inicial do contexto do setor público brasileiro poderá indicar as possíveis determinantes consideradas mais relevantes para investigação. Nesse sentido, apresenta-se a primeira proposição de pesquisa a ser testada no contexto público brasileiro.

Proposição 1: Existem variáveis específicas do contexto do setor público brasileiro que afetam o engajamento no trabalho de servidores públicos. Entre os antecedentes/preditores há variáveis nos diferentes níveis que precisam ser investigadas de forma empírica no contexto público nacional. Os estudos da psicologia 
focam em variáveis do nível individual. Contudo, há de se explorar também o nível organizacional. Análise de estudos longitudinais, realizada por Lesener, Gusy, Jochmann e Wolter (2019), demonstrou que os recursos dos níveis individuais, de equipes/liderança e organizacionais são preditores de engajamento. Contudo, as evidências encontradas pelos autores demonstram que a maneira como o trabalho é organizado, designado e gerido, recursos do nível organizacional, são mais importantes para engajamento no trabalho do que recursos do nível individual. Essa análise permite apresentar duas proposições de pesquisa:

Proposição 2: Variáveis do nível organizacional afetam mais o engajamento no trabalho do que variáveis do nível de grupo (equipes de trabalho e de lideranças).

Proposição 3: Variáveis do nível de grupo afetam mais o engajamento no trabalho do que variáveis do nível individual.

A agenda de pesquisa não pode prescindir de uma vinculação com as práticas de gestão de pessoas, abordagem pouco explorada, inclusive na literatura internacional. São necessários estudos sobre engajamento enquanto uma prática de gestão, estudos que possam investigar quais intervenções, no nível organizacional, são mais promissoras no sentido da geração de engajamento no trabalho (Lesener, Gusy, Jochmann, \& Wolter, 2019). Já é sabido que práticas de gestão de pessoas nas organizações são preditoras de engajamento no trabalho (Alfes et al., 2013a), e que o gerente de linha atua como mediador entre essas práticas e o desempenho individual dos funcionários (Alfes, Truss, Soane, Rees, \& Gatenby, 2013b). Contudo, faltam evidências sobre os efeitos de práticas de gestão de pessoas no comportamento de servidores de uma forma geral, não apenas em relação a engajamento (Oliveros \& Schuster, 2017). Estudos recentes têm demonstrado essa relação (práticas e comportamentos) no nível dos indivíduos, sendo os principais resultados encontrados a diminuição da corrupção e do clientelismo (Meyer-Sahling \& Mikkelsen, 2016), e o aumento da motivação (Oliveros \& Schuster, 2017).

Embora não existam evidências na literatura nacional, o amplo estudo realizado por Meyer-Sahling, Schuster e Mikkelsen (2018) indica que as práticas de recrutamento, de promoção e de desempenho impactam o comportamento de servidores públicos. O estudo analisou o resultado de uma survey com mais de 23 mil servidores em dez diferentes países na África, Ásia, Europa e América Latina. Os resultados mostraram que os efeitos das práticas de gestão de pessoas precisam ser entendidos em cada país e instituições, uma vez que os comportamentos variam conforme o contexto social, político e cultural. A pesquisa não analisou o engajamento como variável, e sim variáveis relacionadas com satisfação, desempenho e comprometimento, portanto, analisar como essas práticas determinam o engajamento no trabalho seria uma contribuição relevante para o campo. Duas proposições finais podem ser elencadas a partir dessas reflexões.

Proposição 4: Práticas de gestão de pessoas, como recrutamento, promoção e gestão de desempenho, afetam diretamente o engajamento no trabalho.

Proposição 5: O gerente de linha tem papel mediador entre as práticas de gestão de pessoas e o engajamento no trabalho. Finalmente, recomenda-se a utilização de variados métodos de pesquisa para a investigação do tema. Essa variação seria importante uma vez que a maioria dos estudos sobre engajamento no mundo consiste em estudos psicométricos (Bailey et al., 2017). Como se trata da proposição de um marco analítico, também seria relevante a realização de estudos fatoriais exploratórios e confirmatórios para testagem e confirmação de instrumentos psicométricos de pesquisa. Além disso, a inclusão de estudos com métodos mistos, com a combinação de pesquisas qualitativas, como por exemplo, estudos etnográficos, com pesquisas quantitativas, como estudos inferenciais e experimentos, contribuiria para a geração de novos insights sobre aspectos contextuais de engajamento no trabalho. Isso certamente suscitaria novos desafios ontológicos e epistemológicos para os pesquisadores, gerando avanços significativos no campo (Bailey et al., 2017). 


\section{Considerações Finais}

Este estudo apresentou um mapeamento e uma sistematização dos principais achados na literatura sobre engajamento no trabalho com foco em engajamento no setor público. $\mathrm{O}$ texto explora diversas questóes que envolvem a contextualização do conceito de engajamento no setor público brasileiro. Representa, assim, uma primeira proposta de marco analítico teórico para orientar estudos futuros sobre o tema no contexto público brasileiro, conforme explicitado na agenda de pesquisa e proposições apresentadas.

O estudo contribui de várias maneiras para a teoria e a prática a respeito do engajamento no trabalho. Em termos teóricos, o texto descreveu as dimensóes do conhecimento produzido sobre engajamento no trabalho e no setor público e propôs uma representação gráfica da sua complexidade. Para tal, o estudo mapeou, sistematizou e resumiu os achados da literatura internacional, bem como evidenciou as lacunas no contexto público brasileiro.

Em termos práticos, o estudo propõe a análise de dimensões que ajudem a explicar o engajamento no trabalho no setor público. Esses resultados podem apoiar o desenho de políticas e práticas de gestão de pessoas no setor público com base em evidências e não apenas em modelos normativos-prescritivos tradicionais. Estratégias de recrutamento, promoção, gestão de desempenho e desenvolvimento poderão ser redesenhadas considerando variáveis que influenciem o engajamento no trabalho. Como preditor de desempenho individual e, consequentemente, do desempenho organizacional, o aumento do engajamento no trabalho possibilita a melhoria de entregas em políticas e serviços públicos no geral. O aumento de eficiência, eficácia e efetividade no serviço público depende de pessoas engajadas na realização do trabalho cotidiano e o investimento em ações que aumentem o engajamento possibilita melhores resultados e geração de valores públicos para a sociedade como um todo.

O ensaio não tem a pretensão de exaurir as possibilidades de agenda de pesquisa sobre a temática no setor público brasileiro. Como o construto tem lacunas relevantes, optou-se por não sugerir uma delimitação de variáveis a serem exploradas especificamente, resultando assim na proposta de uma ampla agenda de pesquisa. Em suma, há um espectro de estudos que envolvem antecedentes, moderadores e resultados do engajamento que ainda precisam ser realizados, de modo que possa ser construída uma teoria do engajamento do trabalho no setor público no Brasil. As proposições de pesquisa oferecidas neste estudo são um marco inicial para esse processo de produção de conhecimento e suporte à definição de políticas e práticas organizacionais.

\section{REFERÊNCIAS}

Alfes, K., Shantz, A.D., Truss, C. \& Soane, E.C. (2013a). The link between perceived human resource management practices, engagement and employee behavior: a moderated mediation model. International Journal of Human Resource Management, 24, pp. 330-351. https://doi.org/10.1080/09585192.2012.679950

Alfes, K., Truss, C., Soane, E.C., Rees, C., Gatenby, M. (2013b). The relationship between line manager behavior, perceived HRM practices, and individual performance: examining the mediating role of engagement. Human Resource Management, 52, pp.839-859. https://doi.org/10.1002/hrm.21512

Andrade, D. C. T. (2019). Engajamento no Trabalho no Serviço Público: Um Modelo Multicultural. Revista de Administração Contemporânea 24(3), pp. $49-66$ https://doi.org/10.1590/1982-7849rac2020190148

Bailey, C., Madden, A., Alfes, K.,, Fletcher, L. (2017). The Meaning, Antecedents and Outcomes of Employee Engagement: A Narrative Synthesis. International Journal of Management Reviews, 19, pp. 31-53. https://doi .org/10.1111/ijmr.12077

Bakker, A. B.,, Demerouti, E. (2016). Job Demands-Resources Theory: Taking Stock and Looking Forward. Journal of Occupational Health Psychology. Advance online publication. https://doi.org/10.1037/ocp0000056 
Marizaura Reis de Souza Camões, et al. Engajamento no Trabalho: Conceitos, Teorias e Agenda de Pes...

Bakker, A.B., Hakanen, J.J., Demerouti, E., Xanthopoulou, D. (2007). Job resources boost work engagement, particularly when job demands are high. Journal of Educational Psychology, 99, pp. 274-284. https://doi.org/1 0.1037/0022-0663.99.2.274

Borst, R. T., Kruyen, P. M., Lako, C. J., de Vries, M. S. (2019). The attitudinal, behavioral, and performance outcomes of work engagement: A comparative meta-analysis across the public, semipublic, and private sector. Review of Public Personnel Administration, https://doi.org/10.1177/0734371X19840399

Borst, R.T. (2018) Comparing Work Engagement in People-Changing and People-Processing Service Providers: A Mediation Model With Red Tape, Autonomy, Dimensions of PSM, and Performance. Public Personnel Management, 47(3) pp. 287-313. https://doi.org/10.1177/0091026018770225

Bryson, A., Forth, J.,, Stokes, L. (2017). How much performance pay is there in the public sector and what are its effects? Human Resource Management Journal, 27(4), pp. 581-597.https://doi.org/10.1111/1748-8583.12153

Carpenter, J., Doverspike, D., Miguel, R. F. (2012). Public Service Motivation as a Predictor of Attraction to the Public Sector. Journal of Vocational Behavior 80(2), pp. 509-23. https://doi.org/10.1016/j.jvb.2011.08.004

Chambel, M.J., Farina, A. (2015) HRM and temporary workers' well-being: a study in Portugal and Brazil. Cross Cultural Management - An International Journal 22(3), https://doi.org/10.1108/CCM-07-2013-0105

Chinelato, R. S. C., Ferreira, M.C. R., Valentini, F. (2019). Work engagement: a study of daily changes. Ciências Psicológicas. 13(1), pp. 3-19http://dx.doi.org/10.22235/cp.v13i1.1805

Chinelato, R. S. C., Ferreira, M.C.,, Valentini, F. (2015). Evidence of Validity of the Job Crafting Behaviors Scale. Paidéia (Ribeirão Preto) 25(62), pp. 325-332 https://doi.org/10.1590/1982-43272562201506

Christian, M.S., Garza, A.S., Slaughter, J.E. (2011). Work engagement: a quantitative review and test of its relations with task and contextual performance. Personnel Psychology, 64, pp. 89-136. https://doi.org/10.1111/j.1744-6 570.2010.01203.x

Cooke, D. K., Brant, K.K., Woods, J.M. (2019) The Role of Public Service Motivation in Employee Work Engagement: A Test of the Job Demands-Resources Model. International Journal of Public Administration 42(9) pp.765-775 https://doi.org/10.1080/01900692.2018.151726

Cordioli, D. F. C., Cordioli Junior, J. R., Gazetta, C. E., Silva, A. G.,, Lourenção, L. G. (2019). Occupational stress and engagement in primary health care workers. Revista Brasileira de Enfermagem 72 (6), pp. 1580-1587 https ://doi.org/10.1590/0034-7167-2018-0681

Crawford, E.A., Rich, B.L., Buckman, B., Bergeron, J. (2014). The antecedents and rivers of employee engagement. In Truss, C. et al.(eds), Employee Engagement in Theory and Practice. London: Routledge, pp. pp. 57-81.

Crawford, E.R., Lepine, J.A., Rich, B.L. (2010). Linking job demands and resources to employee engagement and burnout: a theoretical extension and meta-analytic test. Journal of Applied Psychology, 95, pp. 834-848. https: //doi.org/10.1037/a0019364

Cropanzano, R., Mitchell, M. S. (2005). Social Exchange Theory: An Interdisciplinary Review. Journal of Management, 31(6), pp. 874-900. https://doi.org/10.1177/0149206305279602

Demerouti, E., Bakker, A. B., Nachreiner, F.,, Schaufeli, W. B. (2001). The job demandsresources model of burnout. Journal of Applied Psychology, 86, pp. 499-512.

Farina, L. S. A., Rodrigues, G.R.,, Hutz, C. S. (2018) Flow and Engagement at Work: A Literature Review. Psico-USF 23(4), 633-642. https://doi.org/10.1590/1413-82712018230404

Ferreira, M. C., Valentini, F., Damásio, B. F., Mourão, L., Porto, J. B., Chinelato, R.S.C., Novaes, V. P.,, Pereira, M. M. (2016). Evidências adicionais de validade da UWES-9 em amostras brasileiras. Estudos de Psicologia (Natal) 21(4), pp. 435-445 https://doi.org/10.5935/1678-4669.20160042

Fletcher, L., Bailey, C., Alfes, K., Madden, A. (2019) Mind the context gap: a critical review of engagement within the public sector and an agenda for future research. The International Journal of Human Resource Management. 31(1), pp. 6-46 https://doi.org/10.1080/09585192.2019.1674358

Fredrickson, B. L. (2001). The role of positive emotions in positive psychology: The broaden-and-build theory of positive emotions. American Psychologist, 56(3), pp. 218-226. https://doi.org/10.1037/0003-066X.56.3.218 
Gailmard, S. (2010). Politics, Principal-Agent Problems, and Public Service Motivation. International Public Management Journal 13(1), pp. 35-45. https://doi.org/10.1080/10967490903547225

Hakanen, J.J., and Schaufeli, W.B. (2012), 'Do Burnout and Work Engagement Predict Depressive Symptoms and Life Satisfaction? A Three-Wave Seven-Year Prospective Study,' Journal of Affective Disorders, 141, pp. 415-424. https://doi.org/10.1016/j.jad.2012.02.043

Harel, G.H., Tzafrir, S.S. (2002) HRM practices in the public and private sectors: Differences and similarities. Public Administration Quarterly; 2(25), pp. 316-355 https://www.jstor.org/stable/40861844

Harter, J., Schmidt, F. and Hayes, T. (2002). Business-unit level relationship between employee satisfaction, employee engagement and business outcomes: a meta-analysis. Journal of Applied Psychology, 87, pp. 268-279. https://do i.org/10.1037//0021-9010.87.2.268

Jackson, J.M. Filho (2015). Engajamento no trabalho, impedimentos organizacionais e adoecer: a contribuição da Ergonomia da Atividade no setor público brasileiro. Revista Brasileira de Saúde Ocupacional 40(131), pp. 98-108 https://doi.org/10.1590/0303-7657000083013

Jenkins, S.,, Delbridge, R. (2013). Context matters: Examining 'soft'and 'hard' approaches to employee engagement in two workplaces. The International Journal of Human Resource Management, 24(14), pp. 2670-2691. https ://doi.org/10.1080/09585192.2013.770780

Kahn, W. A. (1990). Psychological conditions of personal engagement and disengagement at work. Academy of management journal, 33(4), pp. 692-724. https://doi.org/10.2307/256287

Legge, K. (2005) Human resource managemet: Rethorics and realities (Anniversar.). Palgrave McMilian,

Lesener,T.; Gusy, B.; Jochmann, A., Wolter, C. (2019): The drivers of work engagement: A meta-analytic review of longitudinal evidence, Work \& Stress, https://doi.org/10.1080/02678373.2019.1686440

Llorens, S., Schaufeli, W. B., Bakker, A. B., Salanova, M. (2007). Does a positive gain spiral of resources, efficacy beliefs and engagement exists? Computers in Human Behavior, 23, pp. 825-841. https://doi.org/10.1016/j.chb.2004 .11 .012

Macey W, Schneider B. (2008). The meaning of employee engagement. Industrial and Organizational Psychology, 1, pp. 3-30. https://doi.org/10.1111/j.1754-9434.2007.0002.x

Maslach, C., Leiter, M. P. (1997). The truth about burnout: How organizations cause personal stress and what to do about it. Jossey-Bass.

Meyer, J. P., Stanley, D. J., Herscovitch, L., Topolnytsky, L. (2002). Affective, continuance, and normative commitment to the organization: A meta-analysis of antecedents, correlates, and consequences. Journal of vocational behavior, 61(1), pp. 20-52. https://doi.org/10.1006/jvbe.2001.1842

Meyer, J. P.; Allen, N. J. (1991) A three-component conceptualization of organizational commitment. Human Resource Management Review, v. 1, pp. 61-89. https://doi.org/10.1016/1053-4822(91)90011-Z

Meyer-Sahling, J.-H., Mikkelsen, K. S. (2016). Civil service laws, merit, politicization, and corruption: The perspective of public officials from five East European countries. Public Administration, 94, pp. 1105-1123. https://doi.or $\mathrm{g} / 10.1111 / \mathrm{padm} .12276$

Meyer-Sahling, J.-H.; Schuster, C., Mikkelsen, K. S. (2018). Civil service management in developing countries: what works? Report for the UK Department for International Development (DFID)

Novaes, V. P., Ferreira, M. C., Gabardo-Martins, L. M. D. (2019). Validity evidences regarding the Authentic Leadership Inventory. Estudos de Psicologia (Campinas) 36( ), pp. 1-11 https://doi.org/10.1590/1982-027520 $1936 \mathrm{e} 180058$

Oliveira, D.F., Ferreira, M. C. (2016). O impacto das percepções de justiça organizacional e da resiliência sobre o engajamento no trabalho. Estudos de Psicologia (Campinas). 33(4), pp. $747-755$ https://doi.org/10.1590/1982 $-02752016000400017$

Oliveira, L.B., Rocha, J. C. (2017). Engajamento no trabalho: antecedentes individuais e situacionais e sua relação com a intenção de rotatividade. Revista Brasileira de Gestão de Negócios 19(65), 415-431 https://doi.org/10.7819/r bgn.v19i64.3373 
Marizaura Reis de Souza Camões, et al. Engajamento no Trabalho: Conceitos, Teorias e Agenda de Pes...

Oliveros, V., Schuster, C. (2017). Merit, tenure, and bureaucratic behavior: Evidence from a conjoint experiment in the Dominican Republic. Comparative Political Studies. 0, pp. 1-34. https://doi.org/10.1177/0010414017710 268

Peccei, R. (2013). Employee engagement: An evidence-based review. In S. Bach, M. R. Edwards (Eds.), Managing human resources: Human resource management in transition (5th ed.) (pp. 336-363). Chichester, UK: John Wiley.

Perry, J. L., Hondeghem, A., Wise, L. R. (2010). Revisiting the Motivational Bases of Public Service: Twenty Years of Research and an Agenda for the Future. Public Administration Review 70(5): pp. 681-90 https://www.jsto r.org/stable/40802365

Perry, J. L., Vandenabeele, W. (2015) Public Service Motivation Research: Achievements, Challenges, and Future Directions. Public Administration Review, 75 (5), pp. 692-699. https://doi.org/10.1111/puar.12430

Perry, J. L., Wise, L. R. (1990). The motivational bases of public service. Public administration review, 50(3) pp. 367-373. https://doi.org/10.2307/976618

Purcell, J. (2014). Disengaging from engagement. Human Resource Management Journal, 24(3), pp. 241-254. https: //doi.org/10.1111/1748-8583.12046

Reis, G.; Trullen, J.; Story, J. (2016). Perceived organizational culture and engagement: the mediating role of authenticity. Journal of Managerial Psychology. 31(6), pp. 1091-1105 https://doi.org/10.1108/JMP-05-20150178

Robinson, D., Perryman, S. and Hayday, S. (2004), The Drivers of Employee Engagement. Institute for Employment Studies, Brighton. 73p.

Saks, A.M. (2006). Antecedents and consequences of employee engagement. Journal of Managerial Psychology, 21, pp. 600-619. https://doi.org/10.1108/02683940610690169

Salanova, M., Llorens, S., Schaufeli, W. B. (2011). “Yes, I can, I feel good, and I just do it!” On gain cycles and spirals of efficacy beliefs, affect, and engagement. Applied Psychology: An International Review, 60, pp. 255-285. https ://doi.org/10.1111/j.1464-0597.2010.00435.x

Santos, A.; Castanheira, F.; Chambel, M.J.; Amarante, M.V.; Costa, C. (2017). Psychological effects of relational job characteristics: validation of the scale for hospital nurses. Journal of Nursing Management. 25(5). https://doi.o $\mathrm{rg} / 10.1111 /$ jonm. 12468

Schaufeli, W., Salanova, M., Gonzalez-Roma, V., Bakker, A. B. (2002). The measurement of engagement and burnout: A two sample confirmatory factor analytic approach. Journal of Happiness Studies, 3, pp. 71-92. https://doi.or g/10.1023/A:1015630930326

Schaufeli, W.B., Bakker, A.B. (2004) Job demands, job resources and their relationship with burnout and engagement: A multi-sample study. Journal of Organizational Behavior, 25, pp. 293-315. https://doi.org/10.1002/job.248

Schaufeli, W.B. (2014). What is engagement? In Truss, C. et al.(eds), Employee Engagement in Theory and Practice. London: Routledge, pp. 15-35.

Shuck, B. (2011) Integrative Literature Review: Four Emerging Perspectives of Employee Engagement: An Integrative Literature Review. Human Resource Development Review, 10 (3), 304-328.https://doi.org/10.1177/15344843 11410840

Silva, A.L.A. Filho, Ferreira, M.C., Valentini, F. (2019). Validity Evidence of the Ethical Leadership Behavior Scale (ELBS). Psico-USF, 24(2), pp. 349-359 https://doi.org/10.1590/1413-82712019240211

Silva, A.G.; Cabrera, E.M.S.; Gazetta, C.E.; Sodre, P.C.; Castro, J.R.; Cordioli, J. R.; Cordioli, D.F.C.; Lourencao, L.G. (2020). Engagement in primary health care nurses: A cross-sectional study in a Brazilian city. Public Health Nursing. 37 (2), pp. 169-177 https://doi.org/10.1111/phn.12694

Sinval, J.; Pasian, S.; Queirós, C.; Maroco, J. (2018) Brazil-Portugal Transcultural Adaptation of the UWES-9: Internal Consistency, Dimensionality, and Measurement Invariance. Frontiers in Psychology. 9 (0). https://doi .org/10.3389/fpsyg.2018.00353

Soane, E.C. (2013), 'Leadership and Employee Engagement,' in Employee Engagement in Theory and Practice, eds. C. Truss, K. Alfes, R. Delbridge, A. Shantz, and E.C. Soane, London: Routledge. 
Truss,C., Shantz, A., Soane, E., Alfes,K., Delbridge,R. (2013) Employee engagement, organizational performance and individual well-being: exploring the evidence, developing the theory, The International Journal of Human Resource Management, 24(14), pp. 2657-2669, https://doi.org/10.1080/09585192.2013.798921

Valentin, C. (2014). The extra mile deconstructed: A critical and discourse perspective on employee engagement and HRD. Human Resource Development International, 17(4), pp. 475-490. https://doi.org/10.1080/13678868.2 014.932091

Vazquez, A.C.S., Magnan, E.S., Pacico, J. C., Hutz, C. S., Schaufeli, W. B. (2015). Adaptation and Validation of the Brazilian Version of the Utrecht Work Engagement Scale Psico-USF, 20(2) pp. 207-217 https://doi.org/10.1 590/1413-82712015200202

Ventura, M., Salanova,M., Llorens,S. (2015) Professional Self-Efficacy as a Predictor of Burnout and Engagement: The Role of Challenge and Hindrance Demands. The Journal of Psychology, 149(3), pp. 277-302, https://doi.org/1 $\underline{0.1080 / 00223980.2013 .876380}$

Weiss HM. (2002). Deconstructing job satisfaction: Separating evaluations, beliefs, and affective experiences. Human Resource Management Review, 12, pp. 173-194. https://doi.org/10.1016/S1053-4822(02)00045-1

Wright, B. E., Grant, A.M. (2010). Unanswered Questions about Public Service Motivation: Designing Research to Address Key Issues of Emergence and Effects. Public Administration Review, 70(5), pp. 691-700. https://doi. org/10.1111/j.1540-6210.2010.02197.x 